purified from cats' urine by Westall, was named 'cat-spot'. In most of the Felidæ it appears to be an alternative to taurine for the excretion of organic sulphur. The Kenya blotched genet has a peculiarity unique among the animals studied in that it excretes very large quantities of cystine. The question as to how so much cystine can be kept in solution in these urines might have some relevance to the study of the prevention of cystine-stone formation in man.

Dr. Datta showed that methyl histidine, which occurs variably in human urine, is always present in laboratory cats which are fed mainly on meat. It is not excreted by animals such as rats, mice, rabbits and guinea pigs, the diets of which are mostly of vegetable origin. By experiments on man, it has been possible to demonstrate that methyl histidine in the urine is probably derived from ingested anserine, a known constituent of muscle. Anserine is hydrolysed in the body to produce beta-alanine, which is further metabolized, and methyl histidine, which is excreted. Thus a peculiarity which superficially resembles an inborn trait turns out on chemical analysis to be mainly a question of diet.

Prof. D. C. Harrison (Queen's University, Belfast) dealt with the rare hereditary disease familial methæmoglobinæmia. He reviewed work done in collaboration with Prof. H. Barcroft, Dr. Q. H. Gibson and others. In methæmoglobinæmia, an abnormally large proportion of the blood pigment hæmoglobin $(\mathrm{Hb})$ is changed to the corresponding ferric compound methæmoglobin $(M e t-H b)$, which is useless for oxygen transport. In normal blood, the equilibrium $H b \stackrel{\longmapsto}{\rightleftharpoons}$ Met-Hb lies far to the left owing to the action of enzyme oxidation-reduction systems in the red blood corpuscles. These systems reduce the methæmoglobin which is constantly being formed from hæmoglobin and prevent the methæmoglobin from accumulating in more than traces. In the type of methæmoglobinæmia caused by certain drugs or (in infants) by nitrates in drinking water, the oxidation of hæmoglobin to methæmoglobin becomes so fast that the restoring enzyme systems are temporarily unable to maintain the normal level of hæmoglobin; but conditions return to normal when the offending agent is removed. In familial methæmoglobinæmia, on the other hand, the rate of production of methæmoglobin is normal but its rate of reduction is abnormally slow, so that it may accumulate to form as much as 40 per cent or more of the total blood pigment. Denny observed that large doses of ascorbic acid (acting as a reducing agent) shift the equilibrium back towards normal.

The work of Gibson has shown that the disease is due to an enzyme defect in the red blood cells; there is a shortage of diaphorase I (a flavoprotein enzyme). This shortage was demonstrated by direct assay in the blood of all seven patients who were tested. The values were in every case lower than those of any of the sixteen normal bloods used for comparison. Addition of excess diaphorase I restored full activity. The oxygen dissociation curve of the blood of the patients was found to be shifted to the left, that is, the blood parted with its oxygen less readily than normal. This, coupled with the large amount of pigment present in the abnormal, non-functional state, mrkes it surprising that the patients as a whole were able to lead active, energetic lives. The compensating polycythæmia which was present in the more severe cases may help to explain this.

The disease is apparently due to a mutation of the gene responsible for synthesis of the flavoprotein diaphorase I. In all three families studied, the disease appeared to $b^{6} \theta$ inherited as a recessive Mendelian trait. Prof. Harrison stated that quantitative studies on the blood of relatives of the patients had given no evidence for the presence of detectable genetic carriers. 'I'reatment of the patients (which was successful in all cases) consisted of large daily doses of ascorbic acid continued indefinitely, preferably supplemented by a single dose of methylene blue after the first fow days.

\section{GROWING-POINTS IN CYTOLOGY}

$\mathrm{O}^{\mathrm{N}}$ the opening day of the recent British Association meeting in Belfast, a session was devoted by Section D (Zoology) to the discussion of some recent advances in cytology. The first paper, by $\mathrm{Mr}$. I. C. Smith (Dundee), on the curious cytology of Pharaoh's ant, Monomorium pharaonis L., followed naturally on Prof. Peacock's presidential address (see Nature, September 6, p. 395), which earlier in the day had been concerned with some aspects of hymenopteran reproduction. Pharaoh's ant shares with many other hymenopterans the peculiarity that the males arise from unfertilized eggs by haploid parthenogenesis, or arrhenotoky, with the result that the male germ cells and much of the soma remain haploid. The females, on the other hand, develop from fertilized eggs, so that the female germ cells and much of the soma are diploid. Clearly, the eggs of virgin females can develop only into males,

Since the male germ-line is already haploid, it is obvious that no further reduction can take place in the chromosome number during the maturation of spermatozoa. In the hornet, Meves showed as early as 1904 that, during spermatogenesis, the first meiotic division, which is normally a reduction division, is abortive, while oogenesis is normal. Considerable. attention has therefore been paid to the details of the first meiotic division in the spermatogenesis of Pharaoh's ant. Mr. Smith described the untidy nature of this division and the curious fact that about this time a small fragment of eytoplasm separates as a bud. Some have considered this bud to represent a vestigial cell, the remnant of a typical meiotic division; but there are now good reasons for abandoning this view. The division is, in fact, a normal mitosis, and the two daughter cells develop without any further division into spermatids and spermatozoa, which are, of course, haploid. There is therefore no stage in spermatogenesis which corresponds to a normal first meiotic division.

The meeting then passed on to consider an inter. esting paper by Dr. R. J. Goldacre (Chester Beatty Institute, London) on the tail region of Amoeba. Dr. Goldacre began by tilting at the insistence of so many zoologists that the Amoba is an animal without form, a point of view that is perpetuated by such names as Amoeba chaos and Chaos chaos. A text-book Amceba is said to throw out pseudopodia at random from any part of its surface, whereas the real $A$ moeba has an obvious antero-posterior polarity with a wellmarked permanent tail, or rear contracting end. This rear end can easily be distinguished as a group of wrinkles caused by a contraction of the cortical gel, which in the tail is liquefying to be squeezed forward up the central channel of the Amceba.

That the tail region of an $A m o b a$ is relatively permanent is shown by the fact that the animal has 
never been seen to reverse, even when watched for as long as a week. This fact can also be demonstrated by staining a living $A$ moeba with neutral red. 'T'he stain becomes concentrated in the tail, which can then be seen to keep its identity for long periods of time. Dr. Goldacre also described how the fate of the tail region can be followed during cell division, and how the tail seems to determine the plane of the division furrow. This furrow is first evident anteriorly, and the tail region is the last part to divide and separate. He therefore suggested that the tail of an Amoba may play some important part in the organization of the cell, surviving possibly throughout its whole life by passing from parent to daughter.

The third contribution to the symposium was a paper by Prof. H. (*. Callan (St. Andrews); but since he was unable to be present it was read in his absence by Dr. Ann R. Sanderson. A description was given of recent research on amphibian oocyte nuclei, with particular reference to their chromosomes. These nuclei have the attraction that when they have been extracted from the yolky cytoplasm they are large enough to be visible to the naked eye. Investigations have shown that there are at least two, and probably three, materials forming the nuclear sap: a fluid phase extending through a jelly phase, and probably an even more rigid centrally placed jelly in which the chromosomes are embedded. 'The whole is surrounded by a membrane pierced by close-packed hexagonal pores.

The chromosomes themselves have been the subject of considerable observation, the necessary preliminary being the development of a technique for their extraction. In Triturus newts the growing oocytes contain chromosomes in the diplotene of meiosis. These chromosomes are almost $800 \mu$ long and are arranged in pairs joined at one or more points of contact. They are of the type known as 'lampbrush', and it is their peculiarity that loops of material sprout out from the chromosome axis and return to their points of origin. There are many structures along the lengths of lampbrush chromosomes which enable one to map them. In a given position there may be a loop which is short and thin, or long and fuzzy, and there are also well-defined regions concerned with the production of nucleoli. When fully formed, these nucleoli detach themselves and migrate to the nuclear membrane. With all these structures available for matching chromosomes, it is possible to show that the contact points between pairs of chromosomes occur in homologous regions, although they differ in different nuclei. Indeed, they show the same type of variation in position as is shown by chiasmata. 'The paper ended with the suggestion that the great value of this oocyte material may prove to lie in what it can teach of gene activity, for in examining these lampbrush chromosomes one may really be seeing genes in action.

'The session ended with a paper by Prof. W. S. Bullough (Birkbeck College, London) on hormones and cell replacement in the epidermis. The research involved was not strictly cytological, but was rather an example of what can be achieved in biological and biochemical work by the use of cytological methods. It had earlier been shown that the most eritical single factor determining the rate of epidermal cell replacement is the rate of energy-production inside the cells. Since it is known that a number of hormones affect the rate of production of energy, a study has now been made of their effect on cell division. Epidermal cells are normally half-starved for glucose, apparently because of their poor powers of absorption of this sugar from the surrounding medium. Insulin is well known to assist the uptake of glucose from the blood by stimulating the hexokinase reaction, and it was found that it also has this effect on epidermis in vitro as evidenced by an induced doubling of the rate of mitosis. It is also known that the pituitary growthhormone inhibits the hexokinase reaction, and experiments have shown that in vitro it powerfully inhibits cell-division. This result suggests that a re-examination of the actions of this hormone is now due, and that the substance may prove to have been misnamed. Possibly its ability to promote growth may be through the induced secretion of other hormones such as insulin.

Attention was then turned to the action of the œestrogenic hormones, which also stimulate epidermal cell-division both in vivo and in vitro, and evidence was briefly reviewed which indicates that they too act by facilitating the hexokinase reaction. However, in vivo the stimulus they exert is only short-lived, and a reaction quickly sets in. This appears to be due, at least in part, to some stimulus to the adrenal cortex, which then actively secretes hormones similar to cortisone. Both in vivo and in vitro cortisone depresses the rate of production of energy and of epidermal mitosis. Androgens do not induce overactivity of the adrenal cortex with growth inhibition, and this fact suggests a reason for the larger body-size of so many male mammals.

The session ended with a lively discussion, ranging in subject from protozoans to cancer.

\section{APPLICATION OF RADIOACTIVITY TO MINERAL DRESSING}

THE third Sir Julius Wernher Memorial Lecture of the Institution of Mining and Metallurgy was given on September 22 at the Royal Institution before a gathering of mineral-dressing engineers who had come to London from many parts of the world to attend the first symposium on this subject to be held in Great Britain. I'he lecturer, Prof. A. M. Gaudin, Richards professor of mineral engineering in the Massachusetts Institute of Technology, chose for his subject "The Application of Radioactivity to Mineral Dressing',

Radioactivity can be used in three ways-as a research tool, for the control of plant processes, and in the direct separation of radioactive from inert minerals. Beta- and gamma-radiation is employed, the limitations of the alpha-rays making them unsuitable. Such properties as self-diffusion, adsorption across the liquid/solid interphase of minerals suspended in fluids, rates and site packings, as well as the mode of movement are of critical research importance in the exploration of surface phenomena used in the process of froth flotation. Prof. Gaudin's lecture not only showed some of the work which is being done but also gave fascinating glimpses of possible new methods of mineral-dressing research. In the complex field of attrition, the use of labelled particles of a closely defined size-range as part of the total mixture of wide-ranging sizes fed into an attrition mill is throwing light on the selective grinding which goes on among these sizes under controlled conditions. Natural radioactivity is in use in north-west Canada to actuate sorting mechanisms which segregate the uranium-bearing ore from inert 